\title{
Hematological Changes in an Ovine Model of Acute Myocardial Infarction
}

\author{
Ezzatollah Fathi (Corresponding author) \\ Department of Clinical Sciences, Faculty of Veterinary Medicine \\ University of Tabriz, Tabriz, Iran. P.O. Box:5166616471
}

Tel: 98-41-1339-2351 E-mail: ez.fathi@ tabrizu.ac.ir or fathi_vet79@yahoo.com

\author{
Elaheh Pishgahzadeh \\ Department of Basic Sciences, Pharmacutical Sciences Branch \\ Islamic Azad University, Tehran, Iran \\ Tel: +98-21-2263-5308Ｅ-mail: pishgahzade@yahoo.com \\ Raheleh Farahzadi \\ Department of Clinical Biochemistry, Faculty of Medical Sciences \\ Tarbiat Modares University, Tehran, Iran \\ Tel: 98-21-6111-3381Ｅ-mail: r.farahzadi@modares.ac.ir
}

Received: May 9, 2013 Accepted: May 23, 2013

doi:10.5296/jbls.v4i2.3648 URL: http://dx.doi.org/10.5296/jbls.v4i2.3648

\begin{abstract}
To diagnose acute myocardial infarction, selected cardiac markers as well as hematological and biochemical indices have been studied in human being, however, rare investigations were done on the values of hematologic analysis in an ovine model of myocardial infarction. To observe the change of the values in hematologic parameters in sheep, acute myocardial infarction was induced by ligation of left anterior descending coronary artery. For this purpose, ten healthy sheep were randomly divided into two group (5 each), the control group (group I; thoracotomy without myocardial infarction) and the experimental group (group II; with myocardial infarction). Animal in each group subjected for the hematologic analysis 1 week post-myocardial infarction. In comparison of hematologic analysis between two groups, the
\end{abstract}


mean values of hemoglobin, white blood cell, red blood cell, platelets, mean corpuscular volume, mean corpuscular hemoglobin and mean corpuscular hemoglobin concentration showed a significant increase in myocardial infarction group $(\mathrm{P}<0.05)$. In conclusion, we could observe the alterations in early hematologic mean values in an ovine model of experimental acute myocardial infarction.

Keywords: Hematologic, Left anterior descending coronary artery, Myocardial infarction, Sheep model

\section{Introduction}

Today, acute myocardial infarction (MI) is the foremost cause of mortality in many countries around the world. When studying MI in large mammals, pigs or sheep are usually used. We chose sheep because, unlike pigs, whose cardiomyocytes have up to 32 nuclei, ovine cardiomyocytes have only 1-4 nuclei, thus being more similar to the human (Adler et al., 1996). In addition, pigs are more prone to develop irreversible ventricular fibrillation than sheep, this leading to higher mortality. A detailed guide with a practical, safe and reliable for induction of MI in ovine models by ligating the main diagonal branch of the left anterior descending (LAD) coronary artery has been reported previously (Kim et al., 2005; Rabbani et al., 2008). Many studies have been published for hematologic and biochemical analysis in relation to acute MI in human (Friedman et al., 1974; Jan et al., 1975; Zalokar et al., 1981; Tahnk-Johnson and Sharkey, 1993; Kobayashi et al., 2001), however, few studies for the observation of alterations in these indices from acute MI has been accomplished (Dodds et al., 1980; Nikolaidis et al., 2003; Aronson et al., 2007). The present study was designed to explore the relationship between the extent of myocardial injury following coronary ligation and the degree of hemodynamic changes in sheep within 1 week after LAD ligation.

\section{Material and Methods}

All procedures were approved by the Laboratory Animal Care and Use Committee of the University of Tehran, and performed in accordance with the Guide for Care and Use of Laboratory Animals, published by the US National Institutes of Health (NIH publication 85-23, revised 1996). Ten healthy, non-obese, adult, male sheep weighing 30-35 kg were randomly divided into two groups ( $\mathrm{n}=5$ each) including Group I (without MI or sham-operated control group) and Group II (with MI) with age- and sex-matched ones. During the study, the animals had free access to water and were fed with a mixed diet of hay and sheep pellets. All animals were housed for 1 week in the animal house so they would be adapted to the environment. They were examined by a veterinarian and a cardiologist, clinically, and some were excluded from the study if any serious morbidity was detected. Animals in group II were subjected to coronary artery ligation after lateral thoracotomy. Surgical procedures were performed under general anesthesia by intravenous injection of sodium pentobarbital $(30 \mathrm{mg} / \mathrm{kg})$ and electrocardiographic monitoring (Kim et al., 2005; Rabbani et al., 2008). Acute MI was inducted by ligating the second diagonal branch of the LAD, as described previously by Rabbani et al. (2008). This method has been documented as a practical, reliable and safe ovine model of inducing MI in paraclinical investigations. After surgical preparation/drape, a 15- to 20-cm-long left lateral thoracotomy incision was carried out through the fourth intercostals 


\section{Al Macrothink Institute ${ }^{\mathrm{TM}}$}

space. After the pericardium was opened, the coronary anatomy was inspected. The second diagonal branch of LAD coronary artery was ligated using a curved round needle and 6-0 prolene suture at a point approximately $40 \%$ distant from its base. Occlusion of the coronary artery was confirmed by the cyanotic appearance of the ischemic area (Fig.1), and ventricular hypokinesia plus ST-segment changes on electrocardiography (ECG). The thoracotomy was closed (pericardium with 5-0 prolene, muscles and skin with 2-0 Vicryl sutures) and a chest tube was placed. For anti-arrhythmic prophylaxis, lidocaine was given as an intravenous bolus dose just before ligation of the diagonal branch $(2 \mathrm{mg} / \mathrm{kg})$ and $15-20 \mathrm{~min}$ there after $(1 \mathrm{mg} / \mathrm{kg})$. Cases stayed at animal ICU for $24 \mathrm{~h}$ after surgery and then were discharged if there were no perioperational morbidities. All animals were studied one week after ligation. In group I, the thorax and pericardium were opened, but the LAD was not ligated; these animals comprise the control group referred to hereafter as sham-operated control group. Monitoring for cardiac function was assessed both clinically and echocardiographically 1-2 days after induction of MI (Fathi et al., 2013). Blood samples were collected from jugular vein 1 week after MI and hematological parameters were assessed from both groups. Laboratory data obtained were performed within 1 week of the MI using commercially available kits (Pars-Azmoon, IRAN).

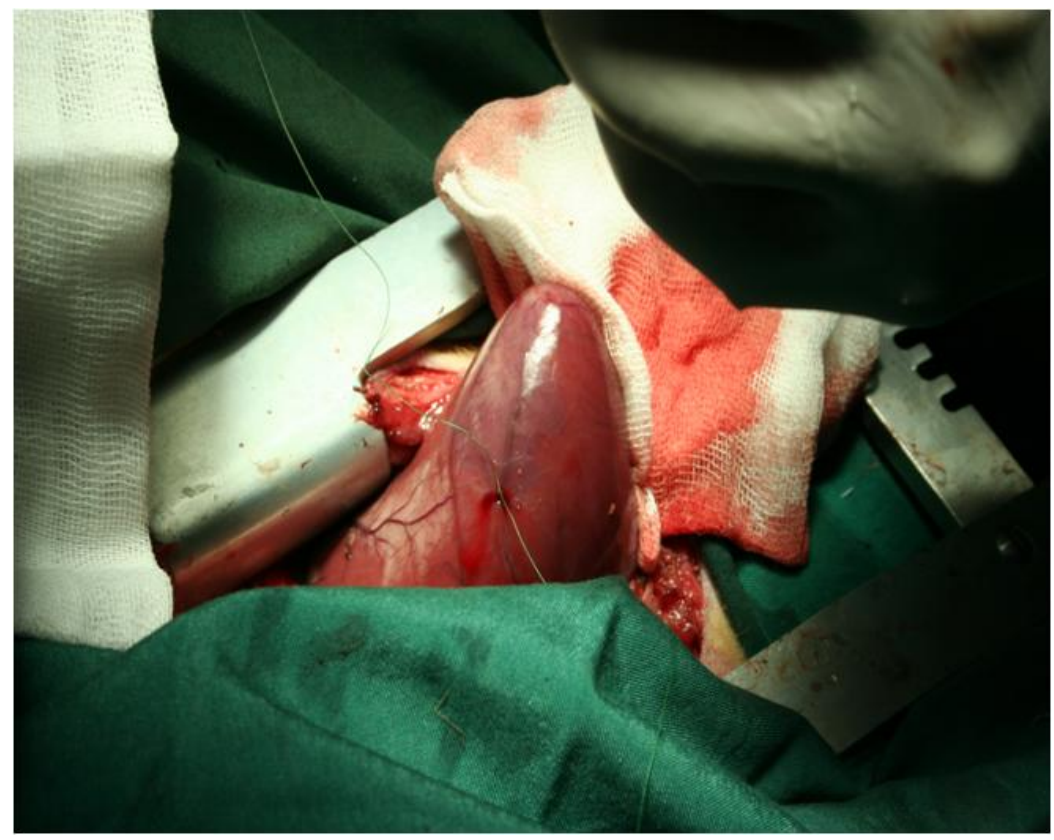

Figure 1. Ischemic bluish discoloration (Hypokinesia) of the infarct area indicated induction of MI.

The data related to hematological indices of packed cell volume (PCV), hemoglobin (Hgb), number of white blood cells (WBCs) and red blood cells (RBCs), platelets (PLT), mean corpuscular volume $(\mathrm{MCV})$, mean corpuscular hemoglobin $(\mathrm{MCH})$, mean corpuscular hemoglobin concentration (MCHC) as well as some biochemical parameters; albumin (Alb), total protein $(\mathrm{Tp})$, fibrinogen $(\mathrm{Fb}), \mathrm{Tp} / \mathrm{Fb}$ ratio and bilirubin (Bili) were obtained for each group. Hematological parameters were measured in an automatic hematological analyzer (Vet Hema-screen 18, Hospitex Diagnostics, Italy). Fb was determined quantitatively by heat precipitation method at the day of sampling on centrifuged ethylenediaminetetraacetic acid 
(EDTA) plasma. For determination of $\mathrm{Alb}$ and $\mathrm{Tp}$ serum was separated following centrifugation for $15 \mathrm{~min}$ at $750 \mathrm{~g}$. Serum samples were stored at $-20^{\circ} \mathrm{C}$ until analysed. Alb concentrations were determined with bromocresol green (BCG) method. Tp concentrations were determined using a standard biuret method. Echocardiography was performed using a Toshiba SSA-380A echocardiography system (Toshiba Corporation, Tochigi-ken, Japan) provided with a $3.5-\mathrm{MHz}$ linear ultrasound transducer.

\subsection{Statistical Analysis}

Statistical analysis was performed using SPSS software (Ver. 16, IBM Corporation, USA). Data were reported as mean \pm standard deviation at significance level of $p<0.05$. Outliers were rejected during data processing using the $\mathrm{T}$ procedure (Bolton et al., 2009). Differences between groups were analyzed using two independent sample t-test and considered as statistically significant when the p value was less than 0.05 .

\section{Results}

No inflammatory reaction was detected in the infarcted area indicated by normal plasma $\mathrm{Fb}$ or absence of abnormal swelling at the surgical area. Among hematological values except PCV and $\mathrm{Hgb}$, a significant changes were observed between the two groups $(\mathrm{P}<0.05$; Table 1$)$. Among biochemical values there was only a significant differences in serum Bili between the two groups $(\mathrm{P}<0.05$; Table 2). Echocardiography revealed significant differences between groups (Fathi et al., 2013).

Table 1. Comparison of hematological indices in case (group II) and control (group I) 1 weeks post-MI (Mean \pm SD).

\begin{tabular}{|c|c|c|c|c|c|c|c|c|}
\hline Groups & $\begin{array}{c}\text { PCV } \\
\%\end{array}$ & $\begin{array}{l}\mathrm{Hgb} \\
\mathrm{g} / \mathrm{dl}\end{array}$ & $\begin{array}{c}\text { WBC } \\
\times 10^{3} / \mu 1\end{array}$ & $\begin{array}{c}\mathrm{RBC} \\
\times 10^{6} / \mu \mathrm{l}\end{array}$ & $\begin{array}{c}\text { PLT } \\
\times 10^{3} / \mu 1\end{array}$ & $\begin{array}{c}\mathrm{MCV} \\
\mathrm{Fl}\end{array}$ & $\begin{array}{c}\mathrm{MCH} \\
\mathrm{pg}\end{array}$ & $\begin{array}{c}\mathrm{MCHC} \\
\%\end{array}$ \\
\hline I & $\begin{array}{c}40.82 \pm \\
9.27\end{array}$ & $\begin{array}{c}8.84 \pm \\
1.16\end{array}$ & $\begin{array}{c}7.06 \pm \\
2.89\end{array}$ & $7.70 \pm 1.14$ & $\begin{array}{c}474 \pm \\
40\end{array}$ & $\begin{array}{c}34.05 \pm \\
8.83\end{array}$ & $\begin{array}{c}9.99 \pm \\
2.56\end{array}$ & $\begin{array}{c}24.25 \pm \\
6.64\end{array}$ \\
\hline II & $\begin{array}{c}41.19 \pm \\
1.99\end{array}$ & $\begin{array}{c}11.87 \pm \\
2.72\end{array}$ & $\begin{array}{c}17.01 \pm \\
5.10 *\end{array}$ & $\begin{array}{c}12.10 \pm \\
1.78^{*}\end{array}$ & $\begin{array}{c}859 \\
\pm 213^{*}\end{array}$ & $\begin{array}{c}54.13 \pm \\
2.73 *\end{array}$ & $\begin{array}{c}11.50 \pm \\
1.47\end{array}$ & $\begin{array}{c}28.91 \pm \\
1.43^{*}\end{array}$ \\
\hline $\mathrm{P}$-value & $>0.05$ & $>0.05$ & $<0.05$ & $<0.05$ & $<0.05$ & $<0.05$ & $>0.05$ & $<0.05$ \\
\hline
\end{tabular}

* Statistically significant

Table 2. Comparison of biochemical indices in case (group II) and control (group I) 1 weeks post-MI (Mean \pm SD).

\begin{tabular}{|c|c|c|c|c|c|}
\hline Groups & $\mathrm{Alb}(\mathrm{g} / \mathrm{dl})$ & $\mathrm{Tp}(\mathrm{g} / \mathrm{dl})$ & $\mathrm{Fb}(\mathrm{mg} / \mathrm{dl})$ & $\mathrm{Tp} / \mathrm{Fb}$ ratio & Bili (mg/dl) \\
\hline Parameters & $3.1 \pm 0.06$ & $6.80 \pm 0.97$ & $545.83 \pm 9.21$ & $12.62 \pm .41$ & $1.5 \pm 0.21$ \\
\hline II & $3.5 \pm 0.13$ & $7.10 \pm 0.82$ & $575.50 \pm 7.28$ & $12.46 \pm 1.92$ & $2.5 \pm 0.18^{*}$ \\
\hline P-value & $>0.05$ & $>0.05$ & $>0.05$ & $>0.05$ & $<0.05$ \\
\hline
\end{tabular}

* Statistically significant 


\section{Discussion}

In various animal models such as mice, rat, sheep, dog, goat and pig coronary artery occlusion and hence inducing MI have been reported (Schaper et al., 1970; Pfeffer et al., 1979; Mannion et al., 1996; Shou et al., 1997; Park and Lucchesi, 1999; Wang et al., 2006; Rabbani et al., 2008; Bani Ismail et al., 2009). However, a few studies describing the procedure of coronary artery ligation to induce MI in sheep model (Kim et al., 2003; Rabbani et al., 2008). Inducing MI in large animal models is a practical method for examining novel therapeutic protocols in cardiovascular research. However, these animals, such as sheep, lack good coronary collateral circulation, which may lead to a remarkable incidence of fatal arrhythmias as a result of myocardial ischemia during such procedures (Nevalainen, 1994; Kim et al., 2001).

Changes that might occur in the hematological values following induction of myocardial infarction have not been reported previously in an ovine model, however, hematological and biochemical indices have been published in human being (Tahnk-Johnson and Sharkey, 1993; Kobayashi et al., 2001; Nikolaidis et al., 2003; Aronson et al., 2007). The results of present study were similar to findings in human beings, as well as rat model with acute MI (Lee et al., 2008; Bani Ismail et al., 2009), that is, except PCV and Hgb, significant changes were seen in WBC, RBC, PLT, MCV and MCHC as a result of acute MI. Reports relating hemostatic factors to incidence of heart disease showed WBCs count was associated with risk of the disease (Friedman et al., 1974; Zalokar et al., 1981; Wilhelmsen et al., 1984; Grimm et al., 1985; Stone and Thorp, 1985; Meade et al., 1986; Kannel et al., 1987).

Anemia can develop during MI even in the absence of overt bleeding (Jan et al., 1975; Tahnk-Johnson and Sharkey, 1993). Therefore, many patients who survive the acute event are discharged with hemoglobin levels that are lower than admission values. The prognostic consequences of the changes in hemoglobin concentrations in patients with acute MI have not been studied (Dodds et al., 1980). Anemia is associated with adaptive hemodynamic changes that may have deleterious effects on myocardial remodeling (Levin et al., 19991 O'Riordan and Foley, 2000; Anand et al., 2004). The presence or the development of anemia during acute MI may impose hemodynamic load during a period of active LV remodeling and contribute to the development of heart disease. High PCV value is associated with an increase in blood viscosity, which may lead to vascular occlusion (Burch and DePasquale, 1965; Lowe et al., 1980). It has also been reported that the PCV level and the severity of the coronary artery disorders are positively associated in IHD patients (Lowe et al., 1980). Among the subjects in one study, PCV exceeded $46.0 \%$ in 19 out of 22 cases (86.4\%) compared to 63 out of 110 controls $(57.3 \%)$ (Kobayashi et al., 2001). In a report from the Netherlands, PCV was shown to be an independent IHD risk factor; the mean PCV value among the cases was also greater than $46.0 \%$ (Knottnerus et al., 1988). In fact, increased PCV and Hgb are considered to be possible risk factors for IHD (Wannamethee et al., 1994; Erikssen et al., 1993; Goubali et al., 1995), but several studies have not supported this (Knottnerus et al., 1988; Sorlie et al., 1981; Carter et al., 1983; Yano et al., 1984; Abu-Zeid and Chapman, 1976). In this study, there was an increase in $\mathrm{PCV}$ value in MI group and a reduction in $\mathrm{Hgb}$ value in control group but no significant differences were seen in comparison with the same mutual group. The explanation appeared to be the opposing influences of a rise in plasma Fb and a fall in PCV (Dodds et al., 1980). A 
reduction in PCV will lead to a reduction in blood viscosity whereas a rise in plasma $\mathrm{Fb}$ concentration will increase red cell aggregation, and thus increase blood viscosity measured at low shear rates (Lowe et al., 1980). After MI, whole blood viscosity, plasma viscosity, and plasma Fb have been shown to be raised (Jan et al., 1975; Fulton and Duckett, 1976; Dodds et al., 1980; Fathi et al., 2013). In our study, plasma Fb in MI group increased but it was not significant compared to the control group.

In one study, Alb and Tp were significantly lower than those in control group (Dodds et al., 1980). In this survey, although Alb and Tp were increased in group II, but significant differences were not observed in comparison with sham-operated control group. The same results were seen in our previous paraclinical investigations carried out in two experimental groups of sheep (control: without MI and case: with MI, n=12 each), 2 days following MI (Fathi et al., 2013). These results are not in agreement with what had been reported by Kuller et al. (1999) and Nuiser et al. (2004) who found that there were significant inverse relation between serum albumin level and risk of coronary heart disease.

High serum total Bili level in patients with MI may suggest that there is a direct correlation between serum total Bili and MI. Our results are agreement with those reported by Olusi et al. (1999) and Nusier et al. (2004). Thus high Bili level might be considered as a risk factor for MI. Biochemical parameters such as Bili, aspartate aminotransferase (AST), lactate dehydrogenase (LDH), creatine kinase (CK), and CK-MB are usually abnormal in severe heart failure due to hepatic congestion (Park et al., 1999; Lee et al., 2008; Granger, 1999). In one previous study in a rat model, there was no significant change in plasma Tp, Alb, glucose, urea, creatinine, total Bili, AST, Alkaline phosphatase (ALP), Gama-glutamil transferase (GGT), and LDH following experimental induction of acute MI at any sampling time, however, a statistically significant differences was noted in plasma concentrations of CK and CK-MB. Serum biochemical and hematological alterations occur following induction of MI have not been reported previously in the sheep model, however, the present study showed that there were not significant changes among biochemical parameters of $\mathrm{Alb}, \mathrm{Tp}$ and $\mathrm{Fb}$ when compared to control group $(\mathrm{P}>0.05)$.

\section{Conclusion}

In conclusion, experimental MI in the sheep model achieved by occlusion of LAD results in significant changes in some hematological and biochemical profile 1 week following acute MI.

\section{Acknowledgment}

The present study was supported by a research grant from the University of Tabriz.

\section{References}

Abu-Zeid, H. A., \& Chapman J. M. (1976). The relation between hemoglobin level and the risk for ischemic heart disease: a prospective study. Journal of Chronic Diseases, 29, 395-403. http://dx.doi.org/10.1016/0021-9681(76)90060-6

Adler, C. P., Friedburg, H., Herget, G. W., Neuburger, M., \& Schwalb H. (1996). Variability of cardiomyocyte DNA content, ploidy level and nuclear number in mammalian hearts. Virchows 
Archiv, 429, 159-164.

Anand, I., McMurray, J. J., Whitmore, J., Warren, M., Pham, A., McCamish, M. A., \& Burton P. B. (2004). Anemia and its relationship to clinical outcome in heart failure. Circulation, 110, 149-154. http://dx.doi.org/10.1161/01.CIR.0000134279.79571.73

Aronson, D., Suleiman, M., Agmon, Y., Suleiman, A., Blich, M., Kapeliovich, M., Beyar, R., Markiewicz, W., \& Hammerman H. (2007). Changes in haemoglobin levels during hospital course and long-term outcome after acute myocardial infarction. European Heart Journal, 28, 1289-1296. http://dx.doi.org/10.1093/eurheartj/ehm013

Bani Ismail, Z., Abu Abeeleh, M., Alzaben, K. R., Abu-Halaweh, S. A., Aloweidi, A. K., Al-Ammouri, I. A., Al-Essa, M. K., Jabaiti, S. K., Alsmady, M. M., \& Al-Majali A. (2009). Effects of experimental acute myocardial infarction on blood cell counts and plasma biochemical values in a nude rat model (Crl:NIH-Fox1RNU). Comparative Clinical Pathology, 18, 433-437. http://dx.doi.org/10.1007/s00580-009-0827-6

Bolton, S., \& Charles B. (2009). Pharmaceutical Statistics: Practical and clinical applications. (5rd ed.). Informa Healthcare: New York.

Burch, G. E., \& DePasquale N. P. (1965). Hematocrit, viscosity and coronary blood flow. Diseases of the Chest, 48, 225-232. http://dx.doi.org/10.1378/chest.48.3.225

Carter, C., McGee, D., Reed, D., Yano, K., \& Stemmermann G. (1983). Hematocrit and the risk of coronary heart disease: the Honolulu Heart Program. American Heart Journal, 105, 674-679. http://dx.doi.org/10.1016/0002-8703(83)90493-3

Dodds, A. J., Boyd, M. J., Allen, J., Bennett, ED., Flute, P. T., \& Dormandy J. A. (1980). Changes in red cell deformability and other haemorrheological variables after myocardial infarction. British Heart Journal, 44, 508-511. http://dx.doi.org/10.1136/hrt.44.5.508

Erikssen, G., Thaulow, E., Sandvik, L., Stormorken, H., \& Erikssen J. (1993). Haematocrit: a predictor of cardiovascular mortality? Journal of Internal Medicine, 234, 493-499. http://dx.doi.org/10.1111/j.1365-2796.1993.tb00783.x

Fathi, E., Farahzadi, R., \& Ahmadi-Hamedani M. (2013). Clinicopathological study in an ovine model of experimental acute myocardial infarction. Iranian Journal of Veterinary Research, Shiraz University, 14(1), 35-41.

Friedman, G. D., Klatsky, A. L., \& Siegelaub A. B. (1974). The leukocyte count as a predictor of myocardial infarction. New England Journal of the Medicine, 290, 1275-1278. http://dx.doi.org/10.1056/NEJM197406062902302

Fulton, R. M., \& Duckett K. (1976). Plasma-fibrinogen and thromboemboli after myocardial infarction. Lancet, ii,1161-1164. http://dx.doi.org/10.1016/S0140-6736(76)91680-9

Goubali, A., Voukiklaris G., Kritsikis, S., Viliotou, F., \& Stamatis D. (1995). Relation of hematocrit values to coronary heart disease, arterial hypertension, and respiratory impairment in occupational and population groups of the Athens area. Angiology, 46, 719-725. 
http://dx.doi.org/10.1177/000331979504600811

Granger D. N. (1999). Ischemia-reperfusion: mechanisms of microvascular dysfunction and the influence of risk factors for cardiovascular disease. Microcirculation, 6, 167-178. doi:10.1038/sj. mn.730008.

Grimm, R. H., Neaton, J. D., \& Ludwig W. (1985). Prognostic importance of the white cell count for coronary, cancer and all cause mortality. Journal of the American Medical Association, 254, 1932-1937. http://dx.doi.org/10.1001/jama.1985.03360140090031

Jan, K. M., Chien, S., \& Bigger J. T. (1975). Observations on blood viscosity changes after acute myocardial infarction. Circulation, 51, 1079-1084. http://dx.doi.org/10.1161/01.CIR.51.6.1079

Kannel, W. B., Wolf, P. A., Castelli, W. P., \& D'Agostino R. B. (1987). Fibrinogen and risk of cardiovascular disease: The Framingham Study. Journal of the American Medical Association, 258, 1183-1186. http://dx.doi.org/10.1001/jama.1987.03400090067035

Kim, B. O., Tian, H., \& Prasongsukarn K. (2005). Cell transplantation improves ventricular function after a myocardial infarction: a preclinical study of human unrestricted somatic stem cells in a porcine model. Circulation, 112(9 Suppl), 196-104.

Kim, W. G., Shin, Y. C., Hwang, S. W., Lee, C., \& Na C.Y. (2003). Comparison of myocardial infarction with sequential ligation of the left anterior descending artery and its diagonal branch in dogs and sheep. International Journal of Artificial Organs, 26, 351-7.

Kim, W. G., Park, J. J., \& Oh S. I. (2001). Chronic heart failure model with sequential ligation of the homonymous artery and its diagonal branch in the sheep. American Society for Artificial Internal Organs Journal, 47, 667-2. http://dx.doi.org/10.1097/00002480-200111000-00019

Knottnerus, J. A., Swaen, G. M., Slangen, J. J., Volovics, A., \& Durinck J. (1988). Haematologic parameters as risk factors for cardiac infarction, in an occupational health care setting. Journal of Clinical Epidemiology, 41, 67-74. http://dx.doi.org/10.1016/0895-4356(88)90010-8

Kobayashi, T., Miyoshi, Y., Yamaoka, K., \& Yano E. (2001). Relationship between Hematological Parameters and Incidence of Ischemic Heart Diseases among Japanese White-Collar Male Workers. Journal of Occupational Health, 43, 85-89. http://dx.doi.org/10.1539/joh.43.85

Kuller, L., Eichner, J. E., Orchard, T. J., Grandits, G. A., McCallum, L., \& Tracy R. P. P. (1999). The relation between serum albumin levels and risk of coronary hearty disease in the multiple risk factor intervention trail. American Journal of Epidemiology, 134, 1266-1277.

Lee, M. J., Tae, H. J., \& Li Y. H. (2008). Serial values for hematologic and biochemical analysis after myocardial infarction in rats. Korean Journal of Veterinary Service, 31(2), 175-186.

Levin, A., Thompson, C. R., Ethier, J., Carlisle, E. J., Tobe, S., Mendelssohn, D., Burgess, E., 
Jindal, K., Barrett, B., Singer, J., \& Djurdjev O. (1999). Left ventricular mass index increase in early renal disease: impact of decline in hemoglobin. American Journal of Kidney Diseases, 34, 125-134. http://dx.doi.org/10.1016/S0272-6386(99)70118-6

Lowe, G. D., Drummond, M. M., \& Lorimer A. R. (1980). Relation between extent of coronary artery disease and blood viscosity. British Medical Journal, 280, 673-674. http://dx.doi.org/10.1136/bmj.280.6215.673

Mannion, J. D., Blood, V., Bailey, W., Bauer, T. L., Magno, M. G., DiMeo, F., Epple, A., \& Spinale F. G. (1996). The effect of basic fibroblast growth factor on the blood flow and morphologic features of a latissimus dorsi cardiomyoplasty. Journal of Thoracic Cardiovascular Surgery, 111, 19-28. http://dx.doi.org/10.1016/S0022-5223(96)70397-5

Meade, T. W., Brozovic, M., \& Chakrabarti R. R. (1986). Haemostatic function and ischaemic heart disease: Principal results of the Northwick Park Heart Study. Lancet, ii, 533-537. http://dx.doi.org/10.1016/S0140-6736(86)90111-X

Nevalainen, T. (1994). Animal model for cardiovascular research. In: Svendsen, P and Hann, J (ed), Handbook of laboratory animal science. Boca, Raton, CRC Press Inc, 11:43-7.

Nikolaidis, M. G., Protosygellou, M. D., Petridou, A., Tsalis, G., Tsigilis, N., \& Mougios V. (2003). Hematological and Biochemical Profile of Juvenile and Adult Athletes of Both Sexes: Implications for Clinical Evaluation. International journal of sports medicine, 24, 506-511. http://dx.doi.org/10.1055/s-2003-42014

Nusier, M. K., El-Akawi, Z., \& Otoom S. A. A. (2004). The Association of Blood Biochemical Parameters with Myocardial Infarction. Journal of Health Science, 50(6), 666-669. http://dx.doi.org/10.1248/jhs.50.666

Olusi, S. O., Prabha, K., \& Sugathan T. N. (1999). Biochemical Risk Factors for Myocardial Infarction among South Asian Immigrants and Arabs. Saudi Medical Journal, 19, 147-149.

O'Riordan, E., \& Foley R. N. (2000). Effects of anaemia on cardiovascular status. Nephrology Dialysis Transplantation, 15(3), 19-22. http://dx.doi.org/10.1093/oxfordjournals.ndt.a027971

Park, J. L., \& Lucchesi B. R. (1999). Mechanisms of myocardial reperfusion injury. The Annals of Thoracic Surgery, 68, 1905-1912. doi:10.1016/S0003- 4975(99) 01073-5.

Pfeffer, M. A., Pfeffer, J. M., Fishbein, M. C., Fletcher, P. J., Spadoro, J., Kloner, R. A., \& Braunwald E. (1979). Myocardial infarct size and ventricular function in rats. Circulation Research, 44, 503-512. http://dx.doi.org/10.1161/01.RES.44.4.503

Rabbani, S., Ahmadi, H., Fayazzadeh, E., Sahebjam, M., Boroumand, M., Sotudeh, M., \& Nassiri S.M. (2008). Development of an ovine model of myocardial infarction. ANZ Journal of Surgery, 78, 78-81. http://dx.doi.org/10.1111/j.1445-2197.2007.04359.x

Schaper, W., De Brabander, M., \& Lewi P. (1970). DNA synthesis and mitoses in coronary collateral vessels of the dog. Circulation Research, 28, 671-679. http://dx.doi.org/10.1161/01.RES.28.6.671 


\section{Macrothink}

Shou, M., Thirumurti, V., Sharmini, M. A., Lazarous, D. F., Hodge, E., Stiber, J. A., Pettiford, M., Elliot, E., Shah, S. M., \& Unger E. F. (1997). Effect of basic fibroblast growth factor on myocardial angiogenesis in dogs with mature collateral vessels. Journal of the American College of Cardiology, 29, 1102-1106. doi:10.1016/S0735-1097(97) 00014-4.

Sorlie, P. D., Garcia-Palmieri, M. R., Costas, R., \& Havlik R. J. (1981). Hematocrit and risk of coronary heart disease: the Puerto Rico Health Program. American Heart Journal, 101, 456-461. http://dx.doi.org/10.1016/0002-8703(81)90136-8

Stone, M. C., \& Thorp J. M. (1985). Plasma fibrinogen: A major coronary risk factor. The Journal of the Royal College of General Practitioners, 35, 565-569.

Tahnk-Johnson, M. E., \& Sharkey S. W. (1993). Impact of thrombolytic therapy on hemoglobin change after acute myocardial infarction. American Journal of Cardiology, 71, 869-872. http://dx.doi.org/10.1016/0002-9149(93)90842-Z

Wang, J., Bo, H., Meng, X., Wu, Y., Bao, Y., \& Li Y. (2006). A simple and fast experimental model of myocardial infarction in the mouse. Laboratory Investigation, 33, 290-293.

Wannamethee, G., Shaper, A. G., \& Whincup P. H. (1994). Ischaemic heart disease: association with haematocrit in the British Regional Heart Study. Journal of Epidemiology and Community Health, 48, 112-118. http://dx.doi.org/10.1136/jech.48.2.112

Wilhelmsen, L., Svardsudd, K., Korsan-Bengtsen, K., Larsson, B., Welin, L., \& Tibblin G. (1984). Fibrinogen as a risk factor for stroke and myocardial infarction. New England Journal of Medicine, 311, 501-505. http://dx.doi.org/10.1056/NEJM198408233110804

Yano, K., Reed, D. M., \& McGee, D. L. (1984). Ten-year incidence of coronary heart disease in the Honolulu Heart Program. Relationship to biologic and lifestyle characteristics. American Journal of Epidemiology, 119, 653-666.

Zalokar, J. B., Richard, J. L., \& Clande J. R. (1981). Leukocyte count, smoking and myocardial infarction. New England Journal of Medicine, 304, 465-468. http://dx.doi.org/10.1056/NEJM198102193040806

\section{Copyright Disclaimer}

Copyright reserved by the author(s).

This article is an open-access article distributed under the terms and conditions of the Creative Commons Attribution license (http://creativecommons.org/licenses/by/3.0/). 